\title{
Исследование взаимосвязи показателя EVA и стоимости компании на российском рынке капитала
}

\author{
Романов B.C. ${ }^{18}$, Кукина Е.Б. ${ }^{19}$
}

В академической литературе достаточно широко распространена концепџия EVATM20 как механизм, используемый в построении системь управления стоимостью. Теоретическая основа экономической прибыли говорит о том, что EVA - это один из наиболее адекватных инструментов в условиях новой экономики, служащий индикатором эффективности работы компании (в частности, работы ее менеджеров).

Однако, несмотря на свое все большее распространение как в литературе, так и в реальной жизни (в виде роста числа компаний, которые применяют показатель для вышеуказанных иелей), ЕVA постепенно стала подвергаться широкой критике и с точки зрения теоретического обоснования адекватности ее применимости, и при проверке реальных результатов ее использования фирмами.

Многочисленные выводы эмпирических исследований, представленные в зарубежной литературе и рассматривающие вопрос о наличии взаимосвязи между наблюдаемой рыночной стоимостью и ЕVA, свидетельствуют о неоднозначности применимости этого показателя для решения задачи управления стоимостью. $B$ то же время, такая практическая проверка стала осуществляться в первую очередь на развитых рынках капитала (США, Канада), где преимущественно и пользуются услугами разработчиков подхода, и значения показателя для компаний офищиально публикуются. В гораздо меньшей степени исследованы развивающиеся рынки, и на данный момент полученные результаты также неоднозначны.

Российские компании также сегодня решают проблему управления бизнесом, чтобы удовлетворить интересам собственников. Тогда, насколько в рамках современной действительности ЕVА может использоваться как инструмент повышения эффрективности деятельности фирмы? Целью настоящей работы является попытка ответить на вопрос, действительно ли EVA коррелирует со стоимостью на российском рынке капитала, чтобы затем ее можно было применять для управления эффективностью бизнеса.

JEL: $G 30$

Ключевые слова: экономическая добавленная стоимость (ЕVA), стоимость компании, экономическая прибыль, управление стоимостью, доходность

\section{Введение}

Поиск параметра, с помощью которого можно объяснить, а еще лучше предсказать, а значит, и управлять изменяющимся состоянием компании, стал сегодня одной из основных проблем как для менеджеров, так и для собственников компании.

Для акционеров компании важно увеличение ее рыночной стоимости. В свою очередь она выражает собой ожидания инвесторов относительно перспектив развития компании, ее фундаментальную стоимость. В 90-е годы широкое распространение получили методы

\footnotetext{
${ }^{18}$ The Boston Consulting Group, старший консультант, преподаватель кафедры Экономики и финансов фирмы ГУ-ВШЭ.

${ }^{19}$ Стажер-исследователь научно-учебной лаборатории корпоративных финансов факультета экономики ГУВШЭ.

${ }^{20}$ Далее по тексту EVA - Economic Value Added.
}

Выпуск \#4(8), 2008 구의 Электонный журнал Корпоративные Финансы, 2008 
управления стоимостью усилиями менеджмента на основе принципа экономической прибыли, который позволяет в каждый момент времени оценить эффективность деятельности фирмы и принимаемых решений в отношении ее развития. Концепция $\mathrm{VBM}^{21}$ призвана управлять именно фундаментальной стоимостью, а уже через ожидания - и рыночной. Связью между рыночной и фундаментальной стоимостью выступают финансовые показатели, на которых завязана система управления стоимостью, одновременно они же являются прозрачными для восприятия внешним инвестором, который на основе их значений строит свою оценку компании [Волков Д.Л., 2005, Ивашковская И.В., 2004].

Принцип экономической прибыли позволяет учитывать не просто то, что заработала компания, но и альтернативные издержки вложения капитала, что в первую очередь является важным для собственника, поскольку если последние оказываются выше сгенерированной отдачи, то инвестиции не оправданы и требуется вывод средств. В рамках подхода используются различные показатели.

- $\quad$ Абсолютные:

o EVA, CVA и MCVA (добавленная стоимость потока денежных средств и ее модификация) [Ottoson E., Weissenreider F., 1996];

o SVA (Shareholder Value Added - добавленная стоимость акционерного капитала, разработка А Раппапорта [Rappaport A., 1986];

o RI - остаточная экономическая прибыль (в основе - модель Е. Ольсона [Ohlson E., 1995].

- Относительные:

o CFROI (Cash Flow Return On Investments) (разработана The Boston Consulting Group и HOLT Value Associates [Madden B. J., 1998];

о спрэд доходности.

Применение указанных финансовых показателей не является универсальным и зависит от таких факторов, как стадия роста компании, сущность ее деятельности и др. [Волков Д.Л., 2005]. Хотя данные метрики представляется вероятным адаптировать для каждого конкретного случая. В то же время рассматриваемая связь показателя, используемого в системе VBM, с рыночной стоимостью, является одним необходимым слагаемым эффективной работы всей системы управления стоимостью (включающей в себя пять компонентов: стратегическое планирование на основе финансовой модели, учитывающей альтернативные источники вложений средств собственников, создание системы оценки показателей эффективности деятельности компании на всех уровнях ответственности, контроль факторов стоимости, система вознаграждения персонала, коммуникация инвесторов и менеджеров через систему показателей) [Ивашковская И.В., 2003, 2004, 2006].

Таким образом, важным для компании становится определить такую метрику, которая, с одной стороны, хорошо коррелирует с рыночными ожиданиями, с другой - является простым и удобным инструментом управления стоимостью и оценки эффективности использования ресурсов.

В одном из подходов в качестве оценки стоимости используется показатель экономической добавленной стоимости EVA. Корреляция параметра с рыночной стоимостью была протестирована на российском рынке капитала. Полученные результаты показывают, что данный показатель имеет слабую связь с рыночной стоимостью.

Статья построена следующим образом. Сначала рассматривается теоретическое обоснование концепции. Затем проводится обзор литературы, которая посвящена эмпирическим исследованиям целесообразности использования EVA. Последний раздел представлен описанием исследования и полученных результатов для российского рынка капитала.

\footnotetext{
${ }^{21}$ VBM - Value Based Management 


\section{Модель EVA}

Модель экономической добавленной стоимости была разработана и запатентована компанией Stern Stewart \& Co в 1985 году. Первоначальной целью авторов было использование удобной техники для расчета добавленной стоимости, созданной за определенный период времени, которая могла бы, в свою очередь, применяться как руководство для принятия управленческих решений [Bromwich M., Walker M., 1998].

Показатель позволяет инвесторам сравнить доходность, приносимую капиталом компании, с альтернативными издержками вложения своих средств.

EVA определяется как операционная прибыль после налогов. за вычетом затрат на использованный капитал. Источник калькуляции - финансовая отчетность, параметры которой берутся скорректированными. Для расчета EVA используется следующая формула:

$$
E V A=\operatorname{NOPAT}_{(\mathrm{adj}) \mathrm{t}}-\mathrm{WACC} \times \mathrm{CE}_{(\mathrm{adj}) \mathrm{t}-1 .}
$$

В относительных показателях формула преобразуется к следующему виду:

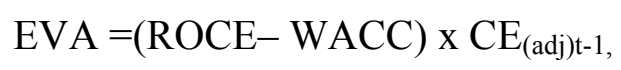

где

$\operatorname{NOPAT}_{(\text {adj)t }}$ (Net Operation Profit After Taxes - чистая операционная прибыль после налогов, скорректированная) = EBIT + вмененные проценты по операционной аренде + расходы, которые компания несет для генерирования результатов не только в текущем периоде, но главным образом в последующие (например, затраты на обучение сотрудников, затраты на НИОКР, на внедрение торговой марки и т.д.) + увеличение резерва LIFO + увеличение резерва по сомнительным долгам + текущая амортизация гудвилла + увеличение отложенных налоговых обязательств - Taxes on EBIT;

WACC (Weighted Average Cost of Capital - средневзвешенная стоимость капитала, представляет собой доходность, требуемую инвесторами при вложении в фирму;

ROCE (Return On Capital Employed) - доходность на вложенный капитал;

$\mathrm{CE}_{\text {(adj)t-1 }}$ (Capital Employed - сумма инвестированного капитала, скорректированная) = Обыкновенные акции + привилегированные акции + доля меньшинства + нераспределенная прибыль + отложенный налог на прибыль + долгосрочный долг, в том числе текущая часть + краткосрочный долг (по которому платятся проценты) + долг по финансовой аренде + резерв LIFO + накопленная амортизация гудвилла + капитализированные расходы на НИОКР + резервы по сомнительным долгам + приведенная стоимость операционной аренды.

Ключевая особенность EVA - корректировки исходных балансовых показателей, имеющие целью отразить действительные направления использования привлеченного капитала и элиминировать воздействие несовершенных стандартов бухгалтерского учета.

В то же время единого мнения относительно необходимых корректировок не существует. Так, авторы идеи Б.Стюарт, Д.Стерн [Stewart B., Stern D.,1999] дают описание 164 возможных корректировок, но на практике предлагают ограничиваться 10-12. Другие исследователи считают, что основные и значимые 5-6 корректировок способны отразить реальную картину деятельности фирмы [Ottoson E., Weissenrieder F., 1996], и показывают, что применение данного метода требует проведения не менее 20 поправок к исходным параметрам финансовой отчетности.

В целом можно выделить следующие основные поправки:

- Капитализация расходов на НИОКР, обучение сотрудников, создание торговой марки и др., цель которых - получение не единомоментного финансового результата, а будущие прибыли.

- Учет всех платных источников финансирования. 
- Капитализация забалансового лизинга и аренды.

- Переучет списания запасав LIFO по методу FIFO.

- Поправка на отложенные налоги на прибыль.

Однако нужно понимать: какие корректировки следует провести - вопрос индивидуальный для каждой компании, и на самом деле унифицированного подхода не может существовать, поскольку в каждом случае использование капитала соответствует конкретным целям, которые ставит перед собой фирма.

Конечной целью инвесторов является увеличение стоимости компании. Модель показывает, что новая стоимость создается только тогда, когда фирме удается принести доходности на вложенный капитал больше, чем альтернативные вложения тех же инвесторов. Отрицательный спрэд доходности и, следовательно, отрицательное текущее значение EVA будет свидетельствовать о частичном разрушении стоимости и в свою очередь являться сигналом, что деятельность менеджеров, направленная на удовлетворение потребностей инвесторов, происходит недостаточно эффективно: необходимо либо что-то менять в управленческом процессе, либо выводить средства из компании.

Несмотря на кажущуюся простоту, в реальной жизни применить подход EVA и привязать к нему мотивационную составляющую деятельности менеджеров и сотрудников компании не всегда легко. Даже такой «простой» показатель требует понимания всей цепочки взаимодействия входящих в него факторов. С другой стороны, его преимущество возможность использования для отдельных подразделений компании. Нужно отметить, что и это утверждение может быть подвергнуто критике, особенно в рамках управления стоимостью диверсифицированной компании, когда ее отдельные подразделения связаны между собой и следовательно, успех/неудача одного будет влиять на значение EVA для другого, а значит, искажать реальную картину деятельности менеджеров и сотрудников подразделений.

Тем не менее, если мы хотим использовать EVA как способ мотивационной составляющей для менеджеров компании, необходимо определить в первую очередь, коррелирует ли она с наблюдаемой рыночной стоимостью бизнеса.

\section{Эмпирическая проверка: результаты исследований}

Создание концепции EVA и ее внедрение в реальную практику управления стоимостью (в начале 90-х годов ее применяли 25 компаний, к концу XX века - уже более 250) [Fernandez P., 2001] повлекло за собой вопросы со стороны исследователей: действительно ли ее можно применять как инструмент управления в компании в терминах взаимосвязи с рыночной стоимостью компании?

Исследования в этом аспекте появились еще в начале использования компаниями EVA, возможно, в большой степени - как ответ на утверждения создателей термина, Б.Стюарта, Д.Стерна, которые призывали забыть все остальные показатели [Biddle G.C. et al., 1997, p. 302].

Вопросы, которые решаются в исследованиях в данном направлении, условно можно разделить на следующие:

1. Можно ли EVA использовать в качестве инструмента, на основе которого строятся схемы вознаграждений для менеджеров? В этом случае работы подчеркивают степень корреляции показателя со стоимостью в целом.

2. В какой степени можно считать EVA лучшим среди других показателей, которые также можно применять для мотивации менеджеров: EVA vs другие показатели экономической прибыли vs финансовые показатели CF vs традиционные бухгалтерские показатели?

В подавляющем большинстве случаев используемая методология этих исследований представляет собой эмпирический анализ, основанный на модели зависимости так или иначе 
выражаемой стоимости компании от вышеуказанных показателей. Подобные исследования представлены в таблице 1.

Ряд исследований основывается на одной и той же модели, когда рассматриваются различные рынки и меняются периоды наблюдений. Так, это относится к исследованиям Г. Биддла и др., Г. Фельтам [Biddle G. et al., 1997; Feltham G. et al., 2004]. Превалирующий подход - рассмотрение какого либо рынка в целом. В этом случае полученные результаты в наилучшей степени являются релевантными для сравнения.

Несколько отличается подход, используемый в исследовании Ч. Лианг, М.Яао [Liang С., Үао М., 2005]. Главной для авторов является одна отрасль - рынок IT-компаний Тайваня. Эта особенность объясняется тем, что они сравнивают различные показатели в рамках использования в VBM системы сбалансированных показателей (BSC, финансовые и нефинансовые). Ввиду технологических особенностей все компании данной отрасли разбиваются на три категории по характеру производства (и поэтому роль финансовых показателей также различна, по мнению авторов). Это позволяет провести более качественный анализ выборки и в большей степени учесть индивидуальные особенности компаний, а следовательно, получить более достоверные результаты.

Одна из спецификаций их модели выглядит следующим образом:

(3) $\mathrm{MV}_{\mathrm{it}}-\mathrm{BV}_{\mathrm{it}}=\mathrm{b}_{0}+\mathrm{b}_{1} * \mathrm{TR}_{\mathrm{it}}+\mathrm{b}_{2} * \mathrm{MKT}_{\mathrm{it}}+\mathrm{b}_{3} * \mathrm{R}_{2} \mathrm{D}_{\mathrm{it}}+\mathrm{b}_{4} * \mathrm{MEXP}_{\mathrm{it}}+\mathrm{b}_{5} * \mathrm{OTHEXP}_{\mathrm{it}}+$ $\mathrm{b}_{6}{ }^{*}$EVAA $_{i t}+\mathrm{b}_{7} \mathrm{CUSTOM}_{\mathrm{it}}+\mathrm{b}_{8} * \mathrm{SUPPLY}_{\mathrm{it}}+\mathrm{b}_{9} * \mathrm{RDME}_{\mathrm{it}}+\mathrm{b}_{10} * \mathrm{RDRTR}_{\mathrm{it}}+\mathrm{b}_{11}$ NPP $_{\mathrm{it}}+$ $\mathrm{b}_{12} * \mathrm{RDDE}_{\mathrm{it}}+\mathrm{PSON}_{\mathrm{it}}+\varepsilon_{\mathrm{it}}$

где финансовые параметры - компоненты чистой прибыли:

$\mathrm{MV}_{\mathrm{it}}$ - рыночная стоимость обыкновенных акций компании;

$\mathrm{BV}_{\mathrm{it}}$ - балансовая стоимость акционерного капитала;

$\mathrm{TR}_{\mathrm{it}}, \mathrm{MKT}_{\mathrm{it}}, \mathrm{R}_{\mathrm{A}} \mathrm{D}_{\mathrm{it}}, \mathrm{MEXP}_{\mathrm{it}}, \mathrm{OTHEXP}_{\mathrm{it}}$ - выручка, маркетинговые расходы, расходы на НИОКР, административные и другие расходы;

нефинансовые параметры:

CUSTOM $_{\text {it }}$, - доля выручки, приходящаяся на тех покупателей, каждый из которых дает не менее $10 \%$ общей выручки;

SUPPLY менее $10 \%$ всех закупок для компании;

$\mathrm{RDME}_{\mathrm{it}}=\mathrm{R} \& \mathrm{D} / \mathrm{MEXP}, \mathrm{RDRTR}_{\mathrm{it}}=\mathrm{R} \& \mathrm{D} /$ total Assets, $\mathrm{RDDE}_{\mathrm{it}}=\mathrm{R} \& \mathrm{D} /$ Net operating revenue,

$\mathrm{NP}_{\mathrm{it}}$ - количество патентов, $\mathrm{PSON}_{\mathrm{it}}$ - количество сотрудников.

Исследование включает в себя большую выборку компаний по каждому из рассматриваемых секторов производства. Кроме того, для проверки устойчивости результатов используют две спецификации модели: относительную (MV/BV) и абсолютную (MV-BV). Характер рассматриваемых взаимосвязей в целом устойчив, но в терминах объяснения стоимости вторая оказывается лучше (критерий - значения $\mathrm{R}^{2}$ ).

Еще одной качественной характеристикой регрессионного анализа, которую используют исследователи, является разделение рассматриваемого промежутка времени на отдельные. Цель - учесть особенности рынка (точнее, его движения) на рыночное состояние компаний. Такой подход применяется в исследовании Д. Мадитиноса и др. [Maditinos D. et al., 2007].

В то же время исследования, касающиеся анализа рассматриваемой взаимосвязи, в большинстве случаев изучают развитые рынки капитала, работы для развивающихся рынков представлены значительно в меньшей степени [Liang C., Yао M., 2005; Wet J., 2005].

Подобное исследование связи оценки стоимости на основе экономической прибыли с 
рыночной стоимостью компаний, проведенное для российского рынка капитала А.В. Бухваловым и Д.Л. Волковым [Бухвалов А.В., Волков Д.Л., 2005] , показало достаточно тесную связь (около 60\%). В их работе проверка касается показателя остаточной чистой прибыли REM (Residual Earnings Model). Выборка построена из 47 компаний, торговавшихся на РТС в период с 2002-го по 2003 год (94 наблюдения). Тестируемые модели имеют вид:

(4) $\quad \mathrm{Cap}_{\mathrm{i}}=\mathrm{a}_{\mathrm{i}}+\mathrm{b}_{\mathrm{i}} * \mathrm{~V}_{\mathrm{i}}+\varepsilon_{\mathrm{i}}$;

(5) $\mathrm{Cap}_{\mathrm{i}}=\mathrm{a}_{\mathrm{i}}+\mathrm{b}_{1 \mathrm{i}} * \mathrm{E}_{\mathrm{i}}+\mathrm{b}_{2 \mathrm{i}} * \mathrm{RE}_{\mathrm{i}} / \mathrm{Ke}+\varepsilon_{\mathrm{i}}$

где

$\mathrm{Cap}_{\mathrm{i}}$ - рыночная капитализация компании на момент оценивания;

$\mathrm{V}_{\mathrm{i}}=\mathrm{E}_{\mathbf{i}}+\mathrm{RE}_{\mathrm{i}} / \mathrm{Ke}$ - фундаментальная стоимость компании;

$\mathrm{E}_{\mathrm{i}}$ - балансовая стоимость собственного капитала;

$\mathrm{Ke}$ - требуемая доходность на собственный капитал (предполагается равной для всех компаний - 30\%).

В меньшей степени подобный анализ взаимосвязи стоимости - показателей делается на основе event study. Event study применяется для качественной характеристики модели. Подобный подход используется П. Фернандесом [Fernandez P.,2001]. Автор разделяет все имеющиеся компании на различные промежутки по степени корреляции $(-100 \% ;+100 \%)$ с шагом 20\%. Дальше анализирует, сколько компаний попадает в тот или иной интервал. Выборка включала в себя 582 компании и 10-летний период наблюдений по каждой. Такой подход дает наглядное представление о характере взаимосвязи: в половине случаев связь между стоимостью и показателем EVA отрицательная. Полученные средние значения по всему промежутку (по взаимосвязям Cor $\left(\Delta \mathrm{MVA}^{22}\right.$; EVA), Cor ( $\triangle \mathrm{MVA}$; NOPAT), Cor ( $\triangle \mathrm{MVA}$; WACC) и их разностей оказываются незначимыми.

В целом результаты исследований достаточно широко разнятся, в зависимости от подхода, времени, исследуемого рынка капитала. Кроме того, для второго направления исследований представляется важным определить момент, с которого можно считать, что компании стали использовать показатель, и здесь могут быть ошибки. Представляется возможным провести исследования по российскому рынку капитала в соответствии с первым подходом к анализу рассматриваемой связи.

\footnotetext{
${ }^{22}$ MVA (Market Value Added) - показатель берется из базы Stern Stewart 1000 (1987—1997), $\Delta \mathrm{MVA}=\mathrm{MVA}_{\mathrm{t}}$ $\mathrm{MVA}_{\mathrm{t}-1}$. 
Таблица 1.

Исследования, рассматривающие взаимосвязь различных факторов со стоимостью компании

\begin{tabular}{|c|c|c|c|c|c|c|}
\hline Исследование & Цель & $\begin{array}{c}\text { Рынок, } \\
\text { отрасль, } \\
\text { период } \\
\text { рассмотрения }\end{array}$ & $\begin{array}{l}\text { Выборка, } \\
\text { источник }\end{array}$ & Спецификация модели & $\begin{array}{c}\text { Степень } \\
\text { объяснения }\end{array}$ & Выводы \\
\hline \multirow{5}{*}{$\begin{array}{l}\text { Чен С., Додд } \\
\text { Дж. Л. (1996) }\end{array}$} & \multirow{5}{*}{$\begin{array}{l}\text { Проверка } \\
\text { способности } \\
\text { показателей } \\
\text { EVA и RI } \\
\text { объяснить } \\
\text { стоимость и } \\
\text { определение } \\
\text { значимости } \\
\text { бухгалтерских } \\
\text { показателей в еe } \\
\text { объяснении. }\end{array}$} & \multirow{5}{*}{$\begin{array}{c}\text { Американский } \\
\text { (1983-1992) }\end{array}$} & \multirow{5}{*}{$\begin{array}{c}556 \\
\text { наблюдений, } \\
\text { Stern Stewart } \\
\text { Database, } \\
\text { Compustat }\end{array}$} & Stock return ${ }^{23}=\mathrm{b}_{0}+\mathrm{b}_{1} *$ EVA/Shares $+\varepsilon$ & $44,9 \%$ & \multirow{5}{*}{$\begin{array}{l}\cdot \quad \text { EVA сама по себе } \\
\text { недостаточна для } \\
\text { объяснения } \\
\text { стоимости. } \\
\bullet \quad \text { Все компоненты, } \\
\text { из которых } \\
\text { складывается EVA } \\
\text { значимы и все вместе } \\
\text { улучшают } \\
\text { объяснение } \\
\text { стоимости, чем по } \\
\text { отдельности. } \\
\bullet \quad \text { Добавленные } \\
\text { бухгалтерские } \\
\text { показатели улучшают } \\
\text { модель. } \\
\text { • Модели, } \\
\text { построенные на } \\
\text { основе RI и ЕVA } \\
\text { дают похожие } \\
\text { значения R }{ }^{2} \text { как } \\
\text { объяснение } \\
\text { стоимости. }\end{array}$} \\
\hline & & & & $\begin{array}{l}\text { Stock return }=\mathrm{b}_{0}+\mathrm{b}_{1} * \text { EVA/Shares }+ \\
\mathrm{b}_{2} * \Delta(\text { EVA/Shares })+\mathrm{b}_{3} * \text { spread }+ \\
\mathrm{b}_{4}{ }^{* \text { Capital growth }+\varepsilon}\end{array}$ & $41,5 \%$ & \\
\hline & & & & $\begin{array}{l}\text { Stock return }=\mathrm{b}_{0}+\mathrm{b}_{1} * \text { EVA/Shares }+ \\
\mathrm{b}_{2}{ }^{*} \Delta(\text { EVA } / \text { Shares })+\mathrm{b}_{3} * \text { spread }+ \\
\mathrm{b}_{4}{ }^{*} \text { Capital growth }+ \\
\mathrm{B}_{5}{ }^{*} \text { EPS }+\mathrm{b}_{6} * \text { ROA }+\mathrm{b}_{7} * \text { ROE }+\varepsilon\end{array}$ & $\begin{array}{l}47,5 \% \\
(36,5 \% \text { для } \\
\text { регрессии } \\
\text { только из } \\
\text { последних } \\
\text { трех } \\
\text { компоненто } \\
\text { в) }\end{array}$ & \\
\hline & & & & Stock return $=\mathrm{b}_{0}+\mathrm{b}_{1} * \mathrm{RI} /$ Shares $+\varepsilon$ & $44 \%$ & \\
\hline & & & & $\begin{array}{l}\text { Stock return }=\mathrm{b}_{0}+\mathrm{b}_{1} * \mathrm{RI} / \text { Shares }+ \\
\mathrm{b}_{2} * \Delta(\mathrm{RI} / \text { Shares })+\mathrm{b}_{3} * \text { spread }+ \\
\mathrm{b}_{4}{ }^{*} \text { Capital growth } \\
\end{array}$ & $41.4 \%$ & \\
\hline \multirow[b]{3}{*}{$\begin{array}{l}\text { Мадитинос Д. } \\
\text { и др. (2007) }\end{array}$} & \multirow[b]{3}{*}{$\begin{array}{l}\text { Сравнение } \\
\text { бухгалтерских } \\
\text { показателей и } \\
\text { EVA в } \\
\text { объяснении } \\
\text { стоимости. }\end{array}$} & \multirow[b]{3}{*}{$\begin{array}{c}\text { Греческий } \\
\text { (До 1999- } \\
\text { 2005) }\end{array}$} & \multirow{3}{*}{$\begin{array}{c}435 \\
\text { наблюдения, } \\
\text { источник -- } \\
\text { ответы } \\
\text { респондентов } \\
\text {, данные с } \\
\text { Greek Capital } \\
\text { Market }\end{array}$} & $\mathrm{P}=\mathrm{b}_{0}+\mathrm{b}_{1} * \mathrm{EPS}^{25}+\varepsilon$ & $4,9-14,1 \%$ & \multirow{3}{*}{$\begin{array}{l}\text { • } \quad \text { Оба типа } \\
\text { переменных значимы, } \\
\text { но EVA лучше } \\
\text { объясняет стоимость, } \\
\text { чем показатель EPS. } \\
\text { - С течением } \\
\text { времени } \\
\text { объясняющая сила } \\
\text { ЕPS падает, а EVA } \\
\text { возрастает. }\end{array}$} \\
\hline & & & & $\mathrm{P}=\mathrm{b}_{0}+\mathrm{b}_{1} * \mathrm{EVA}+\varepsilon$ & $14,3-22,8 \%$ & \\
\hline & & & & $\mathrm{P}=\mathrm{b}_{0}+\mathrm{b}_{1} *$ EPS $+\mathrm{b}_{2} *$ EVA $+\varepsilon$ & $17,5-22,8 \%$ & \\
\hline \multirow[b]{4}{*}{$\begin{array}{l}\text { Биддл Г. и др. } \\
\text { (1996) }\end{array}$} & \multirow{4}{*}{$\begin{array}{l}\text { Сравнение } \\
\text { бухгалтерских } \\
\text { показателей, } \\
\text { EVA и RI в } \\
\text { объяснении } \\
\text { стоимости } \\
\text { Проверка } \\
\text { гипотезы о том, } \\
\text { что применение } \\
\text { EVA } \\
\text { компаниями } \\
\text { оказывает } \\
\text { влияние на } \\
\text { стоимость. }\end{array}$} & \multirow[b]{4}{*}{$\begin{array}{c}\text { Американский } \\
\text { (1983-1994) }\end{array}$} & \multirow{4}{*}{$\begin{array}{l}\quad 6174 \\
\text { наблюдений, } \\
\text { Stern Stewart } \\
\text { Performance } \\
\quad 1000\end{array}$} & $\begin{array}{l}\text { Stock adj return }(\mathrm{t})^{26}=\mathrm{b}_{0}+\mathrm{b}_{1}{ }^{*} \text { Earnings } \\
(\mathrm{t}) / \mathrm{MVE}^{27}(\mathrm{t}-1)+\mathrm{b}_{2} * \text { Earnings(t- } \\
\text { 1)/MVE }(\mathrm{t}-2)+\varepsilon\end{array}$ & $9,04 \%$ & \multirow{4}{*}{$\begin{array}{l}\text { • Показатель } \\
\text { Earnings лучше } \\
\text { коррелирует со } \\
\text { стоимостью. } \\
\text { • Разделение всей } \\
\text { выборки на группы } \\
\text { по степени } \\
\text { использования в } \\
\text { VBM показателя EVA } \\
\text { говорит о том, что } \\
\text { различия в } \\
\text { объяснении } \\
\text { стоимости для } \\
\text { показателей } \\
\text { незначимы. } \\
\text { • ЕVA лучше всех } \\
\text { коррелирует со } \\
\text { стоимостью у тех } \\
\text { компаний, которые ее } \\
\text { действительно } \\
\text { используют в } \\
\text { управленческих } \\
\text { целях. }\end{array}$} \\
\hline & & & & $\begin{array}{l}\text { Stock adj return }(\mathrm{t})= \\
\mathrm{b}_{0}+\mathrm{b}_{1} * \operatorname{EVA}(\mathrm{t}) / \mathrm{MVE}(\mathrm{t}-1)+\mathrm{b}_{2} * \operatorname{EVA}(\mathrm{t}- \\
1) / \mathrm{MVE}(\mathrm{t}-2)+\varepsilon\end{array}$ & $5,07 \%$ & \\
\hline & & & & $\begin{array}{l}\text { Stock adj return }(\mathrm{t})= \\
\mathrm{b}_{0}+\mathrm{b}_{1} * \mathrm{RI}(\mathrm{t}) / \mathrm{MVE}(\mathrm{t}-1)+\mathrm{b}_{2} * \mathrm{RI}(\mathrm{t}- \\
1) / \mathrm{MVE}(\mathrm{t}-2)+\varepsilon\end{array}$ & $6,24 \%$ & \\
\hline & & & & $\begin{array}{l}\text { Stock adj return }(\mathrm{t})= \\
\mathrm{b}_{0}+\mathrm{b}_{1} * \mathrm{CF}(\mathrm{t}) / \mathrm{MVE}(\mathrm{t}-1)+\mathrm{b}_{2}{ }^{*} \mathrm{CF}(\mathrm{t}- \\
1) / \mathrm{MVE}(\mathrm{t}-2)+\varepsilon\end{array}$ & $2,38 \%$ & \\
\hline \multirow[t]{3}{*}{$\begin{array}{l}\text { Фельтам Г. и } \\
\text { др. (2004) }\end{array}$} & \multirow{3}{*}{$\begin{array}{l}\text { Сравнение } \\
\text { бухгалтерских } \\
\text { показателей, } \\
\text { EVA, RI в } \\
\text { объяснении } \\
\text { стоимости. }\end{array}$} & \multirow[t]{3}{*}{$\begin{array}{c}\text { Американский } \\
\text { (1995-1999) }\end{array}$} & \multirow{3}{*}{$\begin{array}{c}2608 \\
\text { наблюдений } \\
\text { Stern Stewart } \\
\text { Performance } \\
1000, \\
\text { Compustat, } \\
\text { Center of } \\
\text { Research and }\end{array}$} & $\begin{array}{l}\text { Stock adj return }(\mathrm{t})=\mathrm{b}_{0}+\mathrm{b}_{1} * \text { Earnings } \\
(\mathrm{t}) / \mathrm{MVE}^{28}(\mathrm{t}-1)+\mathrm{b}_{2} * \text { Earnings }(\mathrm{t}- \\
\text { 1)/MVE }(\mathrm{t}-2)+\varepsilon\end{array}$ & $2,75 \%$ & \multirow[t]{3}{*}{$\begin{array}{l}\bullet \quad \mathrm{RI} \text { лучше } \\
\text { объясняет стоимость, } \\
\text { однако различие с } \\
\text { EVA незначительно. }\end{array}$} \\
\hline & & & & $\begin{array}{l}\text { Stock adj return }(\mathrm{t})= \\
\mathrm{b}_{0}+\mathrm{b}_{1} * \operatorname{EVA}(\mathrm{t}) / \mathrm{MVE}(\mathrm{t}-1)+\mathrm{b}_{2} * \operatorname{EVA}(\mathrm{t}- \\
1) / \mathrm{MVE}(\mathrm{t}-2)+\varepsilon\end{array}$ & $3,62 \%$ & \\
\hline & & & & Stock return $(t)=b_{0}+h_{1} * R I(t) / M V F(t$ & $4,53 \%$ & \\
\hline
\end{tabular}

\footnotetext{
${ }^{23}$ Stock return - среднегодовая доходность акционеров (за счет прироста курсовой стоимости акций и суммы дивидендов) за 10 лет

${ }^{24}$ Capital growth - среднегодовой темп роста капитала за 10 лет

${ }^{25}$ Регрессии строились для разных временных промежутков

${ }^{26}$ Stock adj return- годовая доходность акций фирмы - годовая средневзвешенная доходность рынка.

${ }^{27} \mathrm{MVE}$ - market value of equity через три месяца после начала фискального года.

${ }^{28} \mathrm{MVE}$ - market value of equity через три месяца после начала фискального года.
} 


\begin{tabular}{|c|c|c|c|c|c|c|}
\hline Исследование & Цель & $\begin{array}{c}\text { Рынок, } \\
\text { отрасль, } \\
\text { период } \\
\text { рассмотрения }\end{array}$ & $\begin{array}{l}\text { Выборка, } \\
\text { источник }\end{array}$ & Спецификация модели & $\begin{array}{c}\text { Степень } \\
\text { объяснения }\end{array}$ & Выводы \\
\hline & & & \multirow{2}{*}{$\begin{array}{l}\text { Security } \\
\text { Prices } \\
\text { database }\end{array}$} & $1)+b_{2} * \mathrm{RI}(\mathrm{t}-1) / \mathrm{MVE}(\mathrm{t}-2)+\varepsilon$ & & \multirow{2}{*}{$\begin{array}{l} \\
\text { • } \mathrm{EVA} \mathrm{значительнс} \\
\text { лучше других } \\
\text { показателей } \\
\text { объясняет стоимость. }\end{array}$} \\
\hline & & & & $\begin{array}{l}\text { Stock adj return }(\mathrm{t})= \\
\mathrm{b}_{0}+\mathrm{b}_{1} * \mathrm{CF}(\mathrm{t}) / \mathrm{MVE}(\mathrm{t}-1)+\mathrm{b}_{2}{ }^{*} \mathrm{CF}(\mathrm{t}- \\
1) / \mathrm{MVE}(\mathrm{t}-2)+\varepsilon\end{array}$ & $2,04 \%$ & \\
\hline \multirow{4}{*}{$\begin{array}{l}\text { Фельтам Г. и } \\
\text { др. (2004) }\end{array}$} & \multirow{4}{*}{$\begin{array}{l}\text { Сравнение } \\
\text { бухгалтерских } \\
\text { показателей, } \\
\text { EVA, RI в } \\
\text { объяснении } \\
\text { стоимости. }\end{array}$} & \multirow{4}{*}{$\begin{array}{c}\text { Канадский } \\
\text { (1991-1998) }\end{array}$} & \multirow{4}{*}{$\begin{array}{c}386 \\
\text { наблюдений, } \\
\text { Stern Stewart } \\
\text { \& Co } \\
\text { Canadian } \\
\text { Performance, } \\
\text { Compustat }\end{array}$} & $\begin{array}{l}\text { Stock adj return }(\mathrm{t})=\mathrm{b}_{0}+\mathrm{b}_{1}{ }^{*} \text { Earnings } \\
(\mathrm{t}) / \mathrm{MVE}(\mathrm{t}-1)+\mathrm{b}_{2} * \text { Earnings }(\mathrm{t}- \\
\text { 1)/MVE }(\mathrm{t}-2)+\varepsilon\end{array}$ & $3,19 \%$ & \multirow[t]{4}{*}{$\begin{array}{l}\text { • } \quad \text { EVA значительно } \\
\text { лучше других } \\
\text { показателей } \\
\text { объясняет стоимость. }\end{array}$} \\
\hline & & & & $\begin{array}{l}\text { Stock adj return }(\mathrm{t})= \\
\mathrm{b}_{0}+\mathrm{b}_{1} * \operatorname{EVA}(\mathrm{t}) / \mathrm{MVE}(\mathrm{t}-1)+\mathrm{b}_{2} * \operatorname{EVA}(\mathrm{t}- \\
1) / \mathrm{MVE}(\mathrm{t}-2)+\varepsilon\end{array}$ & $10,72 \%$ & \\
\hline & & & & $\begin{array}{l}\text { Stock return }(\mathrm{t})=\mathrm{b}_{0}+\mathrm{b}_{1} * \mathrm{RI}(\mathrm{t}) / \mathrm{MVE}(\mathrm{t}- \\
1)+\mathrm{b}_{2} * \mathrm{RI}(\mathrm{t}-1) / \mathrm{MVE}(\mathrm{t}-2)+\varepsilon\end{array}$ & $0,07 \%$ & \\
\hline & & & & $\begin{array}{l}\text { Stock adj return }(\mathrm{t})= \\
\mathrm{b}_{0}+\mathrm{b}_{1} * \mathrm{CF}(\mathrm{t}) / \mathrm{MVE}(\mathrm{t}-1)+\mathrm{b}_{2} * \mathrm{CF}(\mathrm{t}- \\
\text { 1)/MVE}(\mathrm{t}-2)+\varepsilon\end{array}$ & $1,04 \%$ & \\
\hline \multirow{6}{*}{$\begin{array}{l}\text { Лианг Ч., Яао } \\
\text { М. (2005) }\end{array}$} & \multirow{6}{*}{$\begin{array}{l}\text { Определение } \\
\text { роли } \\
\text { финансовых и } \\
\text { нефинансовых } \\
\text { показателей в } \\
\text { объяснении } \\
\text { стоимости. }\end{array}$} & \multirow{6}{*}{$\begin{array}{l}\text { Тайваньский, } \\
\text { IT компании } \\
\text { (1998-2000) }\end{array}$} & \multirow{6}{*}{$\begin{array}{c}1827 \\
\text { наблюдений, } \\
\text { Taiwan } \\
\text { Economic } \\
\text { Journal } \\
\text { Databse }\end{array}$} & $\begin{array}{l}\mathrm{MV}_{\mathrm{it}} / \mathrm{BV}_{\mathrm{it}}=\mathrm{b}_{0}+\mathrm{b}_{1} / \mathrm{BV}_{\mathrm{it}}{ }^{+} \\
\mathrm{b}^{*} \text { NIcomponents/BV}+\varepsilon^{29}\end{array}$ & $20,68 \%$ & \multirow{6}{*}{$\begin{array}{l}\text { - } \quad \text { Показатели RI и } \\
\text { EVA незначительно } \\
\text { увеличивают } \\
\text { способность модели } \\
\text { объяснить стоимость. } \\
\text { • } \quad \text { EVA в меньшей } \\
\text { степени, чем RI } \\
\text { улучшает модель. }\end{array}$} \\
\hline & & & & $\begin{array}{l}\mathrm{MV}_{\mathrm{it}} / \mathrm{BV}_{\mathrm{it}}=\mathrm{b}_{0}+\mathrm{b}_{1} / \mathrm{BV}_{\mathrm{it}}{ }^{+} \\
\mathrm{b}^{*} \mathrm{NI} \text { components } / \mathrm{BV}+\mathrm{c}^{*} \mathrm{RI} / \mathrm{BV}+\varepsilon\end{array}$ & $25,87 \%$ & \\
\hline & & & & $\begin{array}{l}\mathrm{MV}_{\mathrm{it}} / \mathrm{BV}_{\mathrm{it}}=\mathrm{b}_{0}+\mathrm{b}_{1} / \mathrm{BVit}+ \\
\mathrm{b}^{*} \text { NIcomponents/BV }+\mathrm{c} * \text { EVA } / \mathrm{BV}+\varepsilon\end{array}$ & $24,35 \%$ & \\
\hline & & & & $\mathrm{MV}_{\mathrm{it}}-\mathrm{BV}_{\mathrm{it}}=\mathrm{b}_{0}+\mathrm{b}^{*}$ NIcomponents $+\varepsilon$ & $65,88 \%$ & \\
\hline & & & & $\begin{array}{l}\mathrm{MV}_{\text {it }}-\mathrm{BV}_{\mathrm{it}}=\mathrm{b}_{0}+\mathrm{b}^{*} \text { NIcomponents } \\
+\mathrm{c}^{*} \mathrm{RI}+\varepsilon\end{array}$ & $74,63 \%$ & \\
\hline & & & & $\begin{array}{l}\mathrm{MV}_{\mathrm{it}} \mathrm{BV}_{\mathrm{it}}=\mathrm{b}_{0}+\mathrm{b}^{*} \text { NIcomponents } \\
+\mathrm{c}^{*} \text { EVA }+\varepsilon\end{array}$ & $74,79 \%$ & \\
\hline \multirow[b]{3}{*}{ Вет Дж. (2005) } & \multirow{3}{*}{$\begin{array}{l}\text { Сравнение } \\
\text { бухгалтерских } \\
\text { показателей и } \\
\text { EVA в } \\
\text { объяснении } \\
\text { стоимости. }\end{array}$} & \multirow{3}{*}{$\begin{array}{c}\text { Восточная } \\
\text { Африка, } \\
\text { промышленны } \\
\text { е компании } \\
\text { (1995-2004) }\end{array}$} & \multirow{3}{*}{$\begin{array}{l}89 \\
\text { наблюдений, } \\
\text { McGregor's } \\
\text { BFA }\end{array}$} & $(\mathrm{MV}-\mathrm{CE}) / \mathrm{CE}=\mathrm{b}_{0}+\mathrm{b}_{1} * \mathrm{CF}^{30} / \mathrm{CE}+\varepsilon$ & $38 \%$ & \multirow{3}{*}{$\begin{array}{l}\cdot \quad \text { EVA слабо } \\
\text { коррелирует с } \\
\text { рыночной } \\
\text { стоимостью } \\
\text { компаний. } \\
\text { • CF значительно } \\
\text { лучше EVA } \\
\text { объясняет стоимость. }\end{array}$} \\
\hline & & & & $\begin{array}{l}(\mathrm{MV}-\mathrm{CE}) / \mathrm{CE}=\mathrm{b}_{0}+\mathrm{b}_{1} *(\mathrm{NOPAT} / \mathrm{CE}- \\
\mathrm{WACC})+\varepsilon\end{array}$ & $8 \%$ & \\
\hline & & & & $(\mathrm{MV}-\mathrm{CE}) / \mathrm{CE}=\mathrm{b}_{0}+\mathrm{b}_{1}{ }^{*} \mathrm{ROA}+\varepsilon$ & $15 \%$ & \\
\hline
\end{tabular}

\footnotetext{
${ }^{29}$ Расшифровка компонентов модели - см. с. 25.
}

${ }^{30} \mathrm{CF}$ - Cash Flow from operations (after tax but before interests and dividends). 


\section{Эмпирическая проверка: российский рынок капитала}

\section{Тестируемая модель}

Выбранная спецификация модели объясняется тем, что для инвестора сегодня важна не просто высокая рыночная стоимость компании, но ее увеличение. Важным также представляется и темп роста этой стоимости. В результате в качестве зависимой переменной рассматривается увеличение доходности собственников компании.

В качестве контрольной переменной в модель добавляется рыночный индекс rRTS, так как изменение рыночной стоимости компании может быть вызвано внешними факторами, присутствующими на рынке капитала.

Формализованная модель № 1 имеет вид:

$$
\mathrm{dTSR}_{i t}=\alpha_{\mathrm{it}}+\beta_{1} * \mathrm{dEVAg}_{\mathrm{it}}+\beta_{2} * \mathrm{rRS}_{\mathrm{t}}+\mathrm{v}_{\mathrm{it}}
$$

где

$\mathrm{dTSR}_{\mathrm{it}}=\mathrm{TSR}_{\mathrm{it}}-\mathrm{TSR}_{\mathrm{it}-1}-$ изменение за период доходности держателей обыкновенных акций (TSR — Total Shareholder Return);

$$
\mathrm{TSR}_{\mathrm{it}}=\left(\operatorname{Eod}_{\mathrm{it}}-\operatorname{Eod}_{\mathrm{it}-1}+\operatorname{Div}_{\mathrm{it}}+/- \text { корректировки }\right) / \operatorname{Eod}_{\mathrm{it}-1},
$$

где

Eod $_{\text {it }}$ - капитализация обыкновенных акций на конец периода $t$;

Divit - сумма выплаченных дивидендов по обыкновенным акциям в период $\mathrm{t}$;

корректировки - относятся к изменению собственного капитала:

1) + выкуп акций (сумма в соответствии с ценой выкупа);

2) - обмен акций дополнительной эмиссии в акции присоединяемых компаний (сумма определяется как количество акций дополнительной эмиссии рассматриваемой компании, умноженное на рыночную котировку акций на момент присоединения);

3) - дополнительная эмиссия акций для продажи через IPO или SPO или другими способами. Используется цена акции, по которой произошла продажа акций.

$$
\begin{aligned}
& \mathrm{dEVAg}_{\mathrm{it}}=\left(\mathrm{EVA}_{\mathrm{it}} \mathrm{EVA}_{\mathrm{it}-1}\right) / \mathrm{EVA}_{\mathrm{it}-1}-\text { темп роста за период показателя EVA. } \\
& \mathrm{EVA}_{\mathrm{it}}=\mathrm{NOPAT}_{\mathrm{it}}-\mathrm{wacc}^{*} \mathrm{CEadj}_{\mathrm{it}-1}
\end{aligned}
$$$$
\text { NOPAT }_{i t}=\text { EBIT }_{i t}-\text { Taxes on } \text { EBIT }_{i t}+\text { Текущая амортизация гудвилла }+
$$
Увеличение отложенных налогов.

(11) $\mathrm{CEadj}=$ Акционерный капитал (включает нераспределенную прибыль) + Доля меньшинства + Краткосрочные кредиты + Краткосрочные займы + Долгосрочные кредиты + Долгосрочные займы + Остальная часть долгосрочного долга + Амортизация гудвилла + Отложенные налоги.

Другие возможные поправки не используются, поскольку данные по таким факторам, как расходы на обучение и НИОКР, раскрываются в недостаточном количестве случаев. Однако там, где эти затраты публикуются, их величина занимает незначительную долю в расходах компаний. Поэтому их исключение не будет оказывать сильного влияния на результаты. 
Средневзвешенные расходы на капитал определяются по следующей формуле:

$$
\begin{aligned}
& \text { wacc }=\mathrm{rd}^{*}(1-\mathrm{t}) * \mathrm{D} / \mathrm{V}+\mathrm{re} * \mathrm{E} / \mathrm{V} \\
& \mathrm{V}=\mathrm{D}+\mathrm{E} \\
& \mathrm{E}=\mathrm{Eod}+\mathrm{Epr}
\end{aligned}
$$

где

rd - требуемая доходность по заемному капиталу;

$\mathrm{t}$ - предельная налоговая ставка (для России - 24\%);

$\mathrm{D}$ - рыночная стоимость долга компании;

E - рыночная стоимость собственного капитала;

Epr - рыночная капитализация привилегированных акций;

$\mathrm{V}$ - рыночная стоимость компании.

rd - рассчитывается с учетом спрэда доходности на основе кредитного рейтинга, по формуле(Дамодаран А., 2005, с. 275 - 279).

$$
\mathrm{rd}=\mathrm{rfus}+\text { CRPrus }+ \text { Default spread, }
$$

где

rfus - безрисковая ставка: годовая доходность по 30-летним американским государственным облигациям Treasury Bonds;

CRPrus - спрэд дефолта для России: определяется по среднегодовому индексу EMBI + Russia (рассчитывается средневзвешенное значение спрэда суверенных еврооблигаций РФ с соответствующими выпусками US Treasuries) - представляет собой дополнительный риск вложений на российском рынке капитала;

Default spread - означает риск вложения в компанию, определяется на основе кредитного рейтинга, который присваивается рейтинговыми агентствами для компаний либо на основе синтетического кредитного рейтинга ${ }^{31}$.

Для определения ге используется метод оценки доходности на основе спрэда:

$$
\text { re }=\text { rfus }+ \text { CRPrus }+\beta l e v *(r m-r f) u s,
$$

где

(rm-rf)us - премия за средний риск инвестирования на рынке акций - рассчитана как среднеарифметическое за 30 лет. В качестве $\mathrm{rm}$ используется рыночная доходность индекса S\&P500. rf - историческое значение доходности по Treasury Bonds;

plev - представляет собой меру оценки систематического риска, рассчитанную для данной компании, определяется исходя из средней меры такого риска по данной отрасли ( $\beta$ un) с учетом финансового рычага по формуле Хамады:

$$
\left.\beta \operatorname{lev}=\beta u^{*}(1+(1-\mathrm{t}) * \mathrm{D} / \mathrm{E})\right)
$$

где

ßun взята как среднее за 5-летний период по опубликованным данным для

\footnotetext{
31 Источник соответствия спрэда дефолта рейтингу - таблицы, публикуемые на сайте А. Дамодарана, http://pages.stern.nyu.edu/ adamodar/ 
соответствующих американских отраслей ${ }^{32}$, которые аналогичны рассматриваемым в настоящей работе.

Предполагается, что требуемые доходности для обыкновенных и привилегированных акций совпадают $\left(\mathrm{re}_{\mathrm{pr}}=\mathrm{re}_{\mathrm{od}}=\mathrm{re}\right)$ ввиду наблюдающейся на российском рынке достаточно сильной корреляции между ценами этих видов акций (корреляция составляет около 99,9\%). Ниже приводятся корреляции для нескольких компаний выборки (для остальных фирм это соотношение такое же).

Таблица 2.

Корреляции цен обыкновенных и привилегированных акций нескольких компаний

\begin{tabular}{|l|l|}
\hline \multicolumn{2}{|l|}{ Балтика } \\
\hline \multicolumn{2}{|l|}{ Ordinary shares } \\
\hline Preffered shares & 0,9993 \\
\hline Ростелеком & Ordinary shares \\
\hline \multicolumn{2}{|}{} \\
\hline Preffered shares & 0,9969 \\
\hline Волгателеком & Ordinary shares \\
\hline \multicolumn{2}{|c|}{} \\
\hline Preffered shares & 0,9997 \\
\hline Уралсвязьинформ \\
\hline \multicolumn{2}{|l}{ Ordinary shares } \\
\hline Preffered shares & 0,9998 \\
\hline
\end{tabular}

Источник: расчеты по ежедневным котировкам акций за 3 года.

$$
\mathrm{rRTS}_{\mathrm{t}}=\left(\mathrm{RTS}_{\mathrm{t}}-\mathrm{RTS}_{\mathrm{t}-1}\right) / \mathrm{RTS}_{\mathrm{t}-1}-\text { темп роста индекса PTC. }
$$

В качестве альтернативного варианта была также протестирована аналогичного вида модель, где независимой переменной вместо EVA выступает показатель REVA - Refined Economic Value Added [Bacidore J.M., Boquist J.A., 1997].

Модель № 2 имеет вид:

$$
\mathrm{dTSR}_{\text {it }}=\alpha_{\text {it }}+\beta_{1} * \mathrm{dREVAg}_{\mathrm{it}}+\beta_{2} * \mathrm{rTS}_{\mathrm{t}}+\mathrm{v}_{\mathrm{it}}
$$

где

$\alpha, \beta_{1}, \beta_{2}$ - оцениваемые параметры;

vit - ошибка.

$$
\mathrm{dREVAg}_{i t}=\left(\mathrm{REVA}_{\mathrm{it}}-\mathrm{REVA}_{\mathrm{it}-1}\right) / \mathrm{REVA}_{\mathrm{it}-1}-\text { темп роста за период }
$$

показателя REVA.

$$
\text { REVA }_{\text {it }}=\text { NOPAT }_{\text {it }}-\text { wacc }^{*} V_{\text {it }-1}
$$

Особенность данного показателя состоит в том, что, в отличие от скорректированного балансового вложенного капитала, в начале периода используется его рыночная оценка, которая измеряется стоимостью всей компании $\left(\mathrm{V}_{\mathrm{it}-1}\right)$. Оба измерителя в целом имеют одинаковую схему построения; но если прибыль соответствует своей рыночной стоимости,

32 Источник отраслевых значений $\beta$ для развитого рынка - данные с сайта А. Дамодарана, http://pages.stern.nyu.edu/ adamodar/

Выпуск \#4(8), 2008

(C) Электронный журнал Корпоративные Финансы, 2008 
остается открытым вопрос, насколько адекватно использовать хоть и скорректированную, но все равно бухгалтерскую стоимость задействованного капитала.

Логика использования второго показателя в том, что на самом деле инвесторы формируют требуемую доходность на основе рыночной стоимости капитала исходя из концепции альтернативных вложений своих средств (в начале рассматриваемого периода). Например, пусть требуемая доходность в начале периода - 10\%, рыночная стоимость капитала оценивается в $\$ 100$, а балансовая - в $\$ 80$. Тогда альтернативные вложения должны принести $100 *(1+0,1)=\$ 110$, а если исходить из балансовой стоимости - то при той же доходности они должны требовать $80 *(1+0,1)=\$ 88$. Инвесторы будут рассматривать не бухгалтерскую, а рыночную стоимость, поскольку по последней можно реализовать имеющиеся ценные бумаги в начале периода. Минус данного подхода в том, что распределение рыночной стоимости по отдельным подразделениям затруднительно.

\section{Данные}

В качестве исходных данных для построения регрессионной модели были отобраны публичные компании, ориентированные на потребительский сектор и не являющиеся проектными (таким образом, их операционные потоки более-менее сглажены) и публикующие консолидированную отчетность по международным стандартам. Итоговая выборка включает период с 2002-го по 2006 год и 11 компаний, представленных в первую очередь телекоммуникационным сектором. В ходе работы анализировались две выборки:

1) первая, состоящая из 49 наблюдений, - наиболее сбалансированная, исключающая только те года для компании, когда она либо еще не имела консолидированной отчетности, либо не торговалась;

2) вторая выборка состоит из 42 наблюдений, не содержит те точки, когда формирование цены на акции компаний происходило в соответствии с факторами, не связанными с направлением их деятельности.

Основой для сбора данных является финансовая отчетность, данные котировок, аналитические отчеты по компаниям.

\section{Полученные результаты и выводы}

В соответствии с имеющимися данными выбиралась спецификация модели: с наличием индивидуального эффекта (FE - fixed effect), случайного индивидуального эффекта (RE random effect $)^{33}$ и сквозной регрессии (OLS - ordinary least squares). Следует отметить, что рассмотрение различных спецификаций для оцениваемых моделей № 1 и № 2 дают схожие результаты.

В таблице 3 представлены описательные статистики рассматриваемых переменных и результаты корреляционного анализа на второй выборке (характер параметров для первой выборки сопоставим). Анализ средних данных и отклонений от среднего параметров говорит о том, все они оказываются незначимыми, и это связано с ограниченностью выборки и большим разбросом данных. В то же время компании в среднем дают увеличение доходности для собственников и падение EVA. Однако если рассмотреть изменение EVA по отдельным компаниям (см. Приложение), то видно, что нельзя однозначно говорить о том, что все они демонстрировали ухудшение эффективности: наблюдается разнонаправленная динамика темпа роста EVA, а в последние годы рассматриваемого периода в большинстве случаев она положительная. В то же время абсолютные значения EVA и REVA говорят о том, что стоимость компаний разрушается. Как и ожидалось, они друг с другом сильно коррелируют и слабо связаны с рыночным индексом.

33 Общий вид таких регрессий описывается уравнением Yit $=\mathrm{BX}+$ ui+eit, где ui - случайный иди фиксированный компонент ошибки, eit - ошибка, $\mathrm{X}$ - матрица значений регрессоров, в том числе свободного члена, В - вектор коэффициентов регрессоров, Yit - вектор значений зависимой переменной.

Выпуск \#4(8), 2008 ○ Электронный журнал Корпоративные Финансы, 2008 


\section{Описательные статистики параметров}

Таблица 3.

\begin{tabular}{|l|l|l|l|l|}
\hline Параметр & dTSR & rRTS & dEVAg & dREVAg \\
\hline Среднее & 0,109 & 0,528 & $-0,112$ & $-1,156$ \\
\hline Медиана & 0,156 & 0,580 & $-0,088$ & $-0,237$ \\
\hline $\begin{array}{l}\text { Стандартное } \\
\text { отклонение }\end{array}$ & 0,707 & 0,280 & 3,857 & 8,866 \\
\hline Минимум & $-1,948$ & 0,078 & $-12,318$ & $-45,753$ \\
\hline Максимум & 1,397 & 0,837 & 18,344 & 27,873 \\
\hline Наблюдений & 42 & 42 & 42 & 42 \\
\hline
\end{tabular}

Таблица 4.

\section{Коррелограмма параметров выборки}

\begin{tabular}{|l|l|l|l|l|}
\hline Параметр & dTSR & rRTS & dEVAg & dREVAg \\
\hline dTSR & 1 & & & \\
\hline rRTS & 0,39 & 1 & & \\
\hline dEVAg & 0,35 & 0,08 & 1 & \\
\hline dREVAg & 0,28 & 0,14 & 0,41 & 1 \\
\hline Наблюдений & 42 & & \\
\hline
\end{tabular}

Вид взаимосвязи между dTSR и факторами моделей №1 и №2 такой, что индивидуальный эффект, который может иметься у компаний, элиминируется за счет вводимой динамики в виде прироста зависимой переменной и темпов роста регрессоров. Модель с индивидуальным эффектом имела бы место, если какой-то пропущенный фактор изменялся бы для компаний с одинаковой скоростью, но выполнение такой предпосылки маловероятно в условиях российского рынка капитала. Формальное тестирование также подтверждает отсутствие индивидуальных эффектов: для первой выборки в общей вариации данных доля, приходящаяся на индивидуальный эффект, незначительна: $6,7 \%$ — в модели № 1 и 9,5\% в модели № 2. Оценка корреляции регрессоров и индивидуального эффекта (corr (ui; BX)) незначительна и составляет $-0,2 \%$ и -7,4\% для моделей № 1 и № 2 соответственно. Кроме того, F test на незначимость индивидуальных эффектов дает положительный результат в обоих случаях. При переходе к меньшей выборке результаты не меняются. Таким образом, мы отвергаем модели с индивидуальным эффектом.

Проводимый тест Хаусмана о различии спецификаций RE и OLS для моделей № 1 и № 2 (для обеих выборок) говорит, что они незначительно друг от друга отличаются (об этом же свидетельствует значение оценки дисперсии индивидуального эффекта ui). Тем не менее итоговые модели выбраны со случайным эффектом, поскольку такой тип является более общим случаем.

Проверка регрессии на первой выборке для анализируемых моделей № 1 и № 2 с учетом поправок на автокорреляцию показывает, что сама модель не отвергается: тест Вальда (Wald $\chi^{2}$ ) говорит о том, что регрессии значимы: $\chi^{2}(3)=13,96$ для модели № 1 и 12,73 для модели № 2. Но в то же время в обоих случаях оцениваемые параметры оказываются незначимыми на уровне 10\% (Pvalue для dEVAg и dREVAg соответственно составляют 11,2 и 19,2\%). Таким образом, в первом приближении можно сказать, что стоимость компаний зависит только от темпа роста всего рынка.

В результате удаления из второй выборки выбивающихся наблюдений за счет того, что сложившаяся рыночная ситуация явным образом не соответствовала фундаментальной стоимости, можно все-таки увидеть некоторую взаимосвязь данных показателей с доходностью собственников. Как и в первом случае, поправка на автокорреляцию улучшает рассматриваемые модели. Итоговые зависимости представлены в нижеследующих таблицах. 


\section{Результаты регрессии зависимости dTSR oT dEVAg (*)}

Таблица 5.

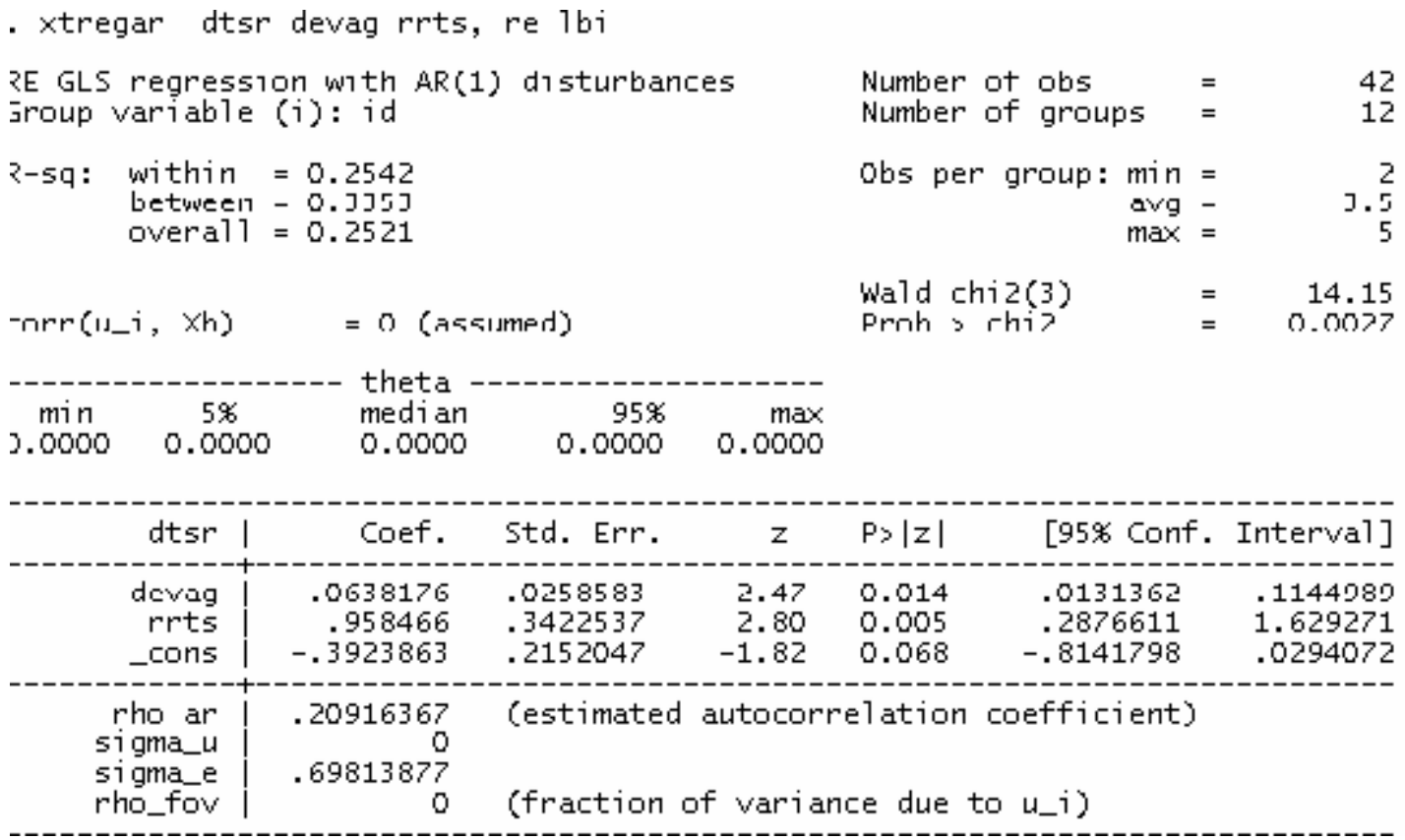

Обозначения:

$\mathrm{dtsr}=\mathrm{dTSR}$, rrts $=\mathrm{rRTS}$, devag $=\mathrm{dEVAg}$, drevag $=\mathrm{dREVAg} ;$

R-sq - Оценки дисперсий внутригрупповой (within), межгрупповой (between) и общей (overall) дисперсии;

Corr (ui, BXit) = 0 предполагается, что регрессоры и индивидуальные эффекты независимы;

z - значение z-статистики для проверки гипотезы о незначимости регрессора;

$\mathrm{P}>|\mathrm{Z}|=$ Pvalue этой статистики;

cons - свободный член в регрессии;

rho_ar - оценка коэффициента автокорреляции ошибок;

sigma_u - оценка стандартного отклонения индивидуального эффекта ui;

sigma_e - оценка стандартного отклонения случайной ошибки eit;

rho_fov - доля дисперсии данных, приходящаяся на индивидуальный эффект. 


\section{Результаты регресси зависимости ATSR oT dREVAg}

Таблица 6.

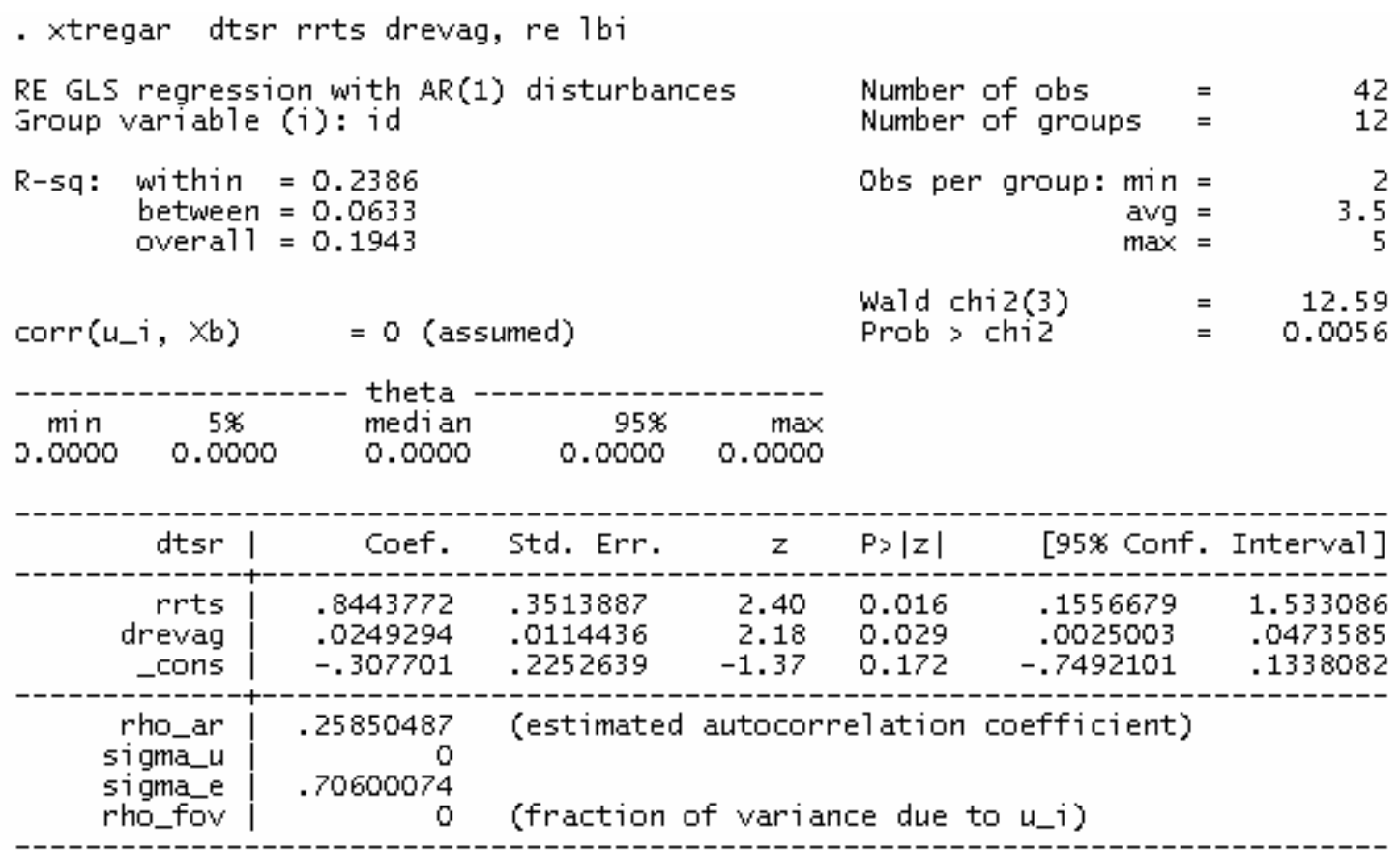

Коэффициенты перед рассматриваемыми переменными являются значимыми на 5\%ном уровне и положительными.

Рассмотрим дополнительную модель, объясняющую насколько стоимость компании зависит от внешнего фактора - индекса РТС: Модель № 3:

$$
\mathrm{dTSR}_{\mathrm{it}}=\alpha_{\mathrm{it}}+\beta_{1}{ }_{\mathrm{rRTS}}+\mathrm{v}_{\mathrm{it}}
$$

Ниже представлены оценки регрессии для модели № 3.

Таблица 7.

\section{Результаты регрессии зависимости ITSR от рыночного индекса}

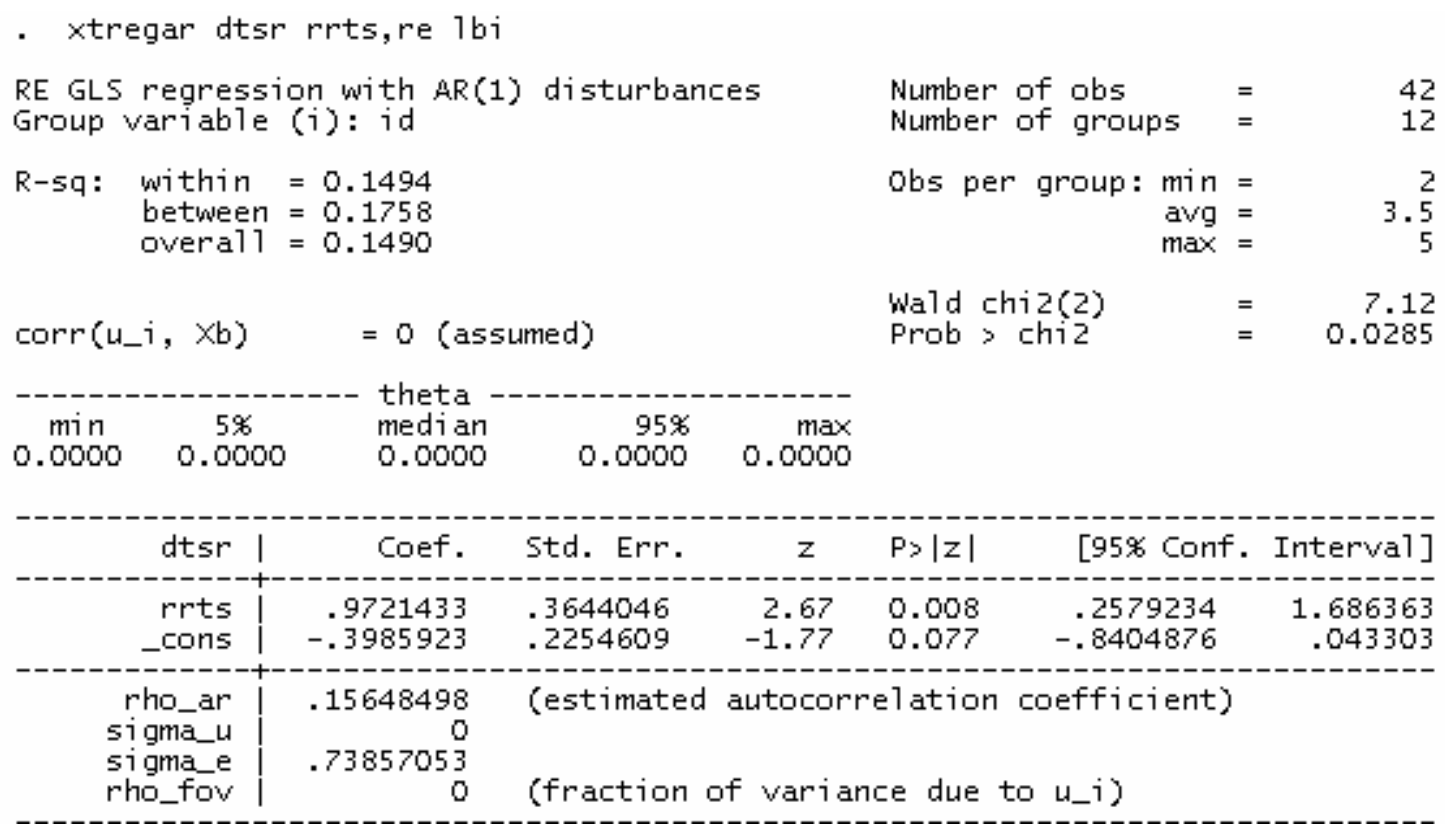

Переходя от модифицированных зависимых переменных к истинным и определяя Выпуск \#4(8), 2008 (C) Электронный журнал Корпоративные Финансы, 2008 
аналоги $\mathrm{R}^{234}$, получаем, что рынок самостоятельно объясняет изменение доходности собственников на 25,8\% (модель № 3). Добавление же показателя dEVAg (переход к модели № 1) увеличивает объясняющую силу регрессии до 32,3\%. dREVAg (переход к модели № 2) - до 32,4\%. Следовательно, оба показателя не могут достаточно хорошо отразить рыночную ситуацию (на них приходится только 6,5\% всего объяснения).

В то же время влияние параметров экономической прибыли на доходность акционеров составляет менее $10 \%$ (для dEVAg - это 6,4\%, для dREVAg - 2,4\% при изменении на $1 \%$ соответствующего фактора).

Таким образом, полученные результаты говорят о том, что показатели экономической добавленной стоимости не способны хорошо объяснять доходность инвесторов. В то же время, возможно, лучшая взаимосвязь будет наблюдаться, если рассмотреть отдельные компоненты показателей экономической прибыли, так как инвесторы могут не воспринимать составной показатель, но в то же время будут обращать внимание на отдельные параметры.

Для получения более достоверных выводов необходимо увеличить количество наблюдений и рассмотреть компании, относящиеся к другим отраслям. Возможно, фактор отрасли также будет оказывать влияние на рассматриваемую взаимосвязь, поскольку российский рынок характеризуется достаточно сильной степенью концентрации капитала, изменение стоимости может быть вызвано сменой собственников компаний или их объединением (что наблюдалось, в частности, в секторе телекоммуникаций), и поэтому характер отраслей в отношении изменения доходности акционеров может отличаться. Кроме того, улучшение модели с учетом автокорреляции может говорить о целесообразности использовать лаговые значения TSR, чтобы отразить запаздывание реакции рынка. Последний действительно получает информацию о результатах компании после какого-то периода времени, прошедшего с начала года. Дополнительной возможностью развития исследования является анализ не абсолютного TSR компании, а его превышения над доходностью рынка.

\section{Список литературы}

1. Дамодаран А. Инвестиционная оценка: инструменты и методы оценки любых активов. М.: Альпина Бизнес Букс, 2005.

2. Теплова Т.В. Инвестиционные рычаги максимизации стоимости компании. Практика российских предприятий. М.: Вершина, 2007.

3. Ивашковская И.В. Развитие стратегического финансового анализа фирмы: принципы, задачи, инструменты // Корпоративные финансы: перспективы и реальность. Стратегические финансовые решения: Сб. ст. участников Четвертой межвузовской конференции молодых ученых /под научной редакцией И.В. Ивашковской М.:ТЕИС, 2007. - С. $6-20$.

4. Ивашковская И.В. Управление стоимостью компании как инновация // Корпоративные финансы: перспективы и реальность. Управление стоимостью компании: Сб. ст. участников Третьей межвузовской конференции молодых ученых / под науч. ред. Т.В.Тепловой. М.: Изд. дом ГУ ВШЭ, 2006. - С. 6-13.

5. Бухвалов А.В., Волков Д.Л. Исследование зависимости между показателями фундаментальной ценности и рыночной капитализации российских компаний // Вестник СПГУб. 2005. № 1(8). С. 26-43.

6. Волков Д.Л. Показатели результатов деятельности: использование в управлении

\footnotetext{
${ }^{34}$ В общем случае связь описывается: $\mathrm{Y}_{\mathrm{it}} \wedge=\mathrm{Y}_{\mathrm{it}}{ }^{\wedge}+(1 \text {-theta })^{*} \mathrm{Y}_{\mathrm{i}}, \mathrm{Y}_{\mathrm{it}} \sim$ — преобразованный $\mathrm{Y}_{\mathrm{i}}$ для определения оценок GLS, $\mathrm{Y}_{\mathrm{i}}$ - усредненное значение $\mathrm{Y}_{\mathrm{it}}$ по времени. $\mathrm{R}^{2}=\operatorname{corr}^{2}\left(\mathrm{Y}_{\mathrm{it}}{ }^{\wedge}, \mathrm{Y}_{\mathrm{it}}\right), \mathrm{Y}_{\mathrm{it}}{ }^{\wedge}, \mathrm{Y}_{\mathrm{it}} \sim^{\wedge}$ — предсказанные значения соответствующих параметров.
} 
стоимостью компании // Российский журнал менеджмента. - 2005. - № 2 (3). - С.342.

7. Ивашковская И.В., Запорожский А.И. Оценка деятельности: новый взгляд // Управление компанией. - 2006. - № 3.

8. Запорожский А.И. Управление стоимостью компании и стратегический анализ на основе модели Modified Cash Value Added (MCVA) // Корпоративные Финансы. 2007. - №1. - С. 78-110.

9. Ивашковская И.В. Управляемая стоимость // Секрет фирмы. - 2004. - № 4 (20).

10. Ивашковская И.В. Управление стоимостью компании: вызовы российскому менеджменту // Российский журнал менеджмента. - 2004. - № 4. - С. 113-132.

11. Ивашковская И.В. Управление стоимостью компании - новый вектор финансовой аналитики фирмы // Управление компанией. - 2004. - № 5 (36). - С. 30-33.

12. Ивашковская И.В. Шпаргалка для собственника // Секрет фирмы. - 2003. - № 5 (21). C. $21-25$.

13. Теплова Т.В. Современные модификации стоимостной модели управления компанией // Вестник МГУ. - 2004. - №1. - С. 1-26.

14. Щербакова О.Н. Методы оценки и управления стоимостью компании, основанные на концепции добавленной стоимости // Финансовый менеджмент. - 2003. - № 6.

15. Янгель Д. Модель EVA: ориентация на стоимость // Консультант. - 2005. - № 3.

16. Rappaport A. Creating Shareholder Value. New York: Free Press, 1986.

17. Stewart B., Stern D. The Quest For Value. The EVA management guide. New York: Harper Business, 1999.

18. Bacidore J.M., Boquist J.A. etc. The Search For The Best Financial Performance Measure // Financial Analysts Journal 1997. No. 53. P. 11-20.

19. Biddle G.C. et al. Does EVAtm Beat Earnings? Evidence on Associations With Stock Returns And Firm Values // Journal of Accounting and Economics. 1997. No. 24. P. 301306.

20. Bromwich M., Walker M. Residual income past and future // Management Accounting Research. 1998. No. 9. P. 391-419.

21. Chen S., Dodd J. Economic Value Added: An Empirical Examination Of A New Corporate Performance Measure // Journal Of Managerial Issues. 1997. Vol. IX (3). P. 318-333.

22. Feltham G.D., Isaac G., Mbagwu C. (2004) Perhaps EVA Does Beat Earninigs - Revisiting Previous Evidence // Journal Of Applied Corporate Finance. 2004. No. 16. P. 83-88.

23. Fernandez P. EVA And Cash Value Added Do Not Measure Shareholder Value Creation // Working paper, IESE Business School. 2001.

24. Liang C., Yao M. The Value-Relevance of Financial and Nonfinancial InformationEvidence from Taiwan's Information Electronics Industry // Review of Quantitative Finance and Accounting. 2005. No. 24. P. 135-157.

25. Madden B.J. The CFROI Valuation Model // The Journal of Investing. 1998. No. 7. P. $31-44$.

26. Maditinos. D., Sevic Z., Theriou N., Dimitriadis E. The Use Of Traditional And Modern Value-Based Performance Measures To Evaluate Companies' Implemented And Future Strategies In The Greek Capital Market: The Case OF EPS And EVA // Journal Of International Research Publications. 2007. No. 2.P. 35-50.

27. Milano G.V. EVA And The "New Economy" // Journal Of Applied Corporate Finance. 2000. No. 13.No. 118-126.

28. Ottoson E., Weissenrieder F. Cash Value Added - A New Method For Measuring Financial Performance // Working Paper, Gothenburg Studies in Financial Economics. 1996.

29. Riberio de Medeiros O. Empirical Evidence On The Relationship Between EVA And Stock Returns In Brazilian Firms // Working Paper, University of Brasilia.2005.

30. Stewart G.B. EVATM: Fact and Fantasy // Journal of Applied Corporate Finance. 1994. No.7. P. $71-84$. 
31. Wet J. EVA Versus Traditional Accounting Measures of Performance as Drivers of Shareholder Value - A Comparative Analysis // Meditari Accountancy Research. 2005. No.13, P. 1-16. 


\section{Приложение}

Таблица 8.

Параметры доходности собственников, экономической прибыли и затрат на капитал

\begin{tabular}{|c|c|c|c|c|c|c|c|c|c|c|}
\hline Наименование & $\begin{array}{c}\text { Отчетный } \\
\text { год }\end{array}$ & TSR & NOPAT & wacc & CEadj, & EVA & REVA & dTSR & dEVAg & dREVAg \\
\hline «Балтика» & 2006 & $50,6 \%$ & 427599 & $12,9 \%$ & 1737885 & 203680 & -111837 & $-38,5 \%$ & $17,0 \%$ & $-428,3 \%$ \\
\hline «Балтика» & 2005 & $89,1 \%$ & 304128 & $14,5 \%$ & 899449 & 174103 & -21171 & $38,7 \%$ & $292,6 \%$ & $67,8 \%$ \\
\hline «Балтика» & 2004 & $50,4 \%$ & 156767 & $14,9 \%$ & 756804 & 44349 & -65686 & $60,2 \%$ & $-12,7 \%$ & $46,7 \%$ \\
\hline «Балтика» & 2003 & $-9,8 \%$ & 151619 & $16,0 \%$ & 631135 & 50779 & -123192 & $-59,9 \%$ & $-25,7 \%$ & $-36,1 \%$ \\
\hline «Балтика» & 2002 & $50,1 \%$ & 155581 & $20,7 \%$ & 421408 & 68348 & -90523 & & & \\
\hline ВБД & 2006 & $165,3 \%$ & 178064 & $13,0 \%$ & 835548 & 69779 & 22669 & $129,7 \%$ & $1834,4 \%$ & $180,4 \%$ \\
\hline ВБД & 2005 & $35,6 \%$ & 98949 & $14,5 \%$ & 711853 & -4023 & -28193 & $49,0 \%$ & $80,5 \%$ & $58,4 \%$ \\
\hline ВБД & 2004 & $-13,4 \%$ & 77838 & $14,8 \%$ & 666340 & -20664 & -67804 & $-5,1 \%$ & $-134,3 \%$ & $-7,7 \%$ \\
\hline ВБД & 2003 & $-8,4 \%$ & 74418 & $16,0 \%$ & 518855 & -8818 & -62936 & & & \\
\hline «Волгателеком» & 2006 & $49,8 \%$ & 114334 & $15,1 \%$ & 1138510 & -57629 & -140842 & $21,6 \%$ & $-42,8 \%$ & $-68,1 \%$ \\
\hline «Волгателеком» & 2005 & $28,2 \%$ & 116411 & $17,0 \%$ & 924190 & -40349 & -83780 & $8,1 \%$ & $-126,7 \%$ & $-20,4 \%$ \\
\hline «Волгателеком» & 2004 & $20,0 \%$ & 102711 & $17,4 \%$ & 691061 & -17800 & -69571 & $-254,2 \%$ & $-53,1 \%$ & $-223,9 \%$ \\
\hline «Волгателеком» & 2003 & $274,3 \%$ & 87624 & $18,2 \%$ & 544711 & -11629 & 56131 & $239,3 \%$ & $-137,8 \%$ & $72,8 \%$ \\
\hline «Волгателеком» & 2002 & $34,9 \%$ & 56759 & $23,7 \%$ & 109490 & 30765 & 32490 & & & \\
\hline «Дальсвязь» & 2006 & $69,3 \%$ & 37461 & $15,2 \%$ & 422571 & -26947 & -27121 & $-64,6 \%$ & $6,6 \%$ & $-792,3 \%$ \\
\hline «Дальсвязь» & 2005 & $133,8 \%$ & 38247 & $16,7 \%$ & 401876 & -28846 & -3039 & $139,7 \%$ & $-12,2 \%$ & $45,8 \%$ \\
\hline «Дальсвязь» & 2004 & $-5,9 \%$ & 29891 & $17,3 \%$ & 321956 & -25720 & -5605 & $-63,2 \%$ & $-10,5 \%$ & $-391,1 \%$ \\
\hline «Дальсвязь» & 2003 & $57,3 \%$ & 21080 & $18,2 \%$ & 243629 & -23286 & 1926 & $-33,4 \%$ & $\begin{array}{r}- \\
1231,8 \%\end{array}$ & $-84,2 \%$ \\
\hline «Дальсвязь» & 2002 & $90,7 \%$ & 19399 & $23,5 \%$ & 89800 & -1748 & 12194 & $73,9 \%$ & $91,3 \%$ & $287,5 \%$ \\
\hline «Дальсвязь» & 2001 & $16,8 \%$ & -1961 & $20,1 \%$ & 90305 & -20102 & -6505 & & & \\
\hline МГТС & 2006 & $35,1 \%$ & 166390 & $15,2 \%$ & 1189589 & -13858 & -148016 & $-17,2 \%$ & $78,7 \%$ & $-37,2 \%$ \\
\hline МГТС & 2005 & $52,2 \%$ & 143703 & $16,9 \%$ & 1234823 & -65090 & -107914 & $58,2 \%$ & $64,4 \%$ & $55,5 \%$ \\
\hline МГТС & 2004 & $-6,0 \%$ & 21527 & $17,8 \%$ & 1151686 & -182970 & -242490 & $-111,8 \%$ & $-697,4 \%$ & $-4575,3 \%$ \\
\hline МГТС & 2003 & $105,8 \%$ & 159789 & $18,2 \%$ & 1001675 & -22946 & 5418 & $102,4 \%$ & $85,1 \%$ & $105,4 \%$ \\
\hline МГТС & 2002 & $3,4 \%$ & 90326 & $23,7 \%$ & 1032948 & -154253 & -101261 & $-13,6 \%$ & $-31,3 \%$ & $-167,9 \%$ \\
\hline МГТС & 2001 & $17,0 \%$ & 78752 & $20,8 \%$ & 944661 & -117438 & -37805 & & & \\
\hline «Ростелеком» & 2006 & $232,9 \%$ & -13688 & $15,3 \%$ & 2039830 & -326719 & -351032 & $205,3 \%$ & $26,7 \%$ & $7,3 \%$ \\
\hline «Ростелеком» & 2005 & $27,6 \%$ & -79167 & $17,1 \%$ & 2140093 & -445682 & -378626 & $37,8 \%$ & $-43,3 \%$ & $-27,0 \%$ \\
\hline «Ростелеком» & 2004 & $-10,2 \%$ & 45331 & $17,6 \%$ & 2022943 & -311087 & -298080 & $-82,3 \%$ & $29,0 \%$ & $-15,0 \%$ \\
\hline «Ростелеком» & 2003 & $72,1 \%$ & -33740 & $18,2 \%$ & 2221687 & -438149 & -259133 & $41,4 \%$ & $16,3 \%$ & $3,4 \%$ \\
\hline «Ростелеком» & 2002 & $30,6 \%$ & -26235 & $23,9 \%$ & 2079529 & -523194 & -268199 & $84,1 \%$ & $-3,7 \%$ & $36,7 \%$ \\
\hline «Ростелеком» & 2001 & $-53,5 \%$ & -40333 & $20,4 \%$ & 2279403 & -504558 & -423863 & $-173,2 \%$ & $-89,7 \%$ & $-419,4 \%$ \\
\hline «СЗтелеком» & 2006 & $78,1 \%$ & 100457 & $15,1 \%$ & 1297789 & -95796 & -93425 & $7,6 \%$ & $19,7 \%$ & $-58,4 \%$ \\
\hline «СЗтелеком» & 2005 & $70,5 \%$ & 71586 & $17,3 \%$ & 1103488 & -119233 & -58972 & $41,6 \%$ & $-253,2 \%$ & $-778,4 \%$ \\
\hline «СЗтелеком» & 2004 & $28,9 \%$ & 80608 & $17,8 \%$ & 643437 & -33760 & -6714 & $14,8 \%$ & $61,2 \%$ & $78,6 \%$ \\
\hline «СЗтелеком» & 2003 & $14,1 \%$ & 15547 & $18,5 \%$ & 552926 & -87020 & -31313 & $26,7 \%$ & $-159,5 \%$ & $-426,3 \%$ \\
\hline «СЗтелеком» & 2002 & $-12,6 \%$ & 53413 & $23,9 \%$ & 364461 & -33533 & -5949 & $11,1 \%$ & $57,8 \%$ & $89,2 \%$ \\
\hline «СЗтелеком» & 2001 & $-23,7 \%$ & -3159 & $20,3 \%$ & 375630 & -79511 & -55284 & & & \\
\hline «Сибирьтелеком» & 2006 & $48,1 \%$ & 66244 & $15,1 \%$ & 1147587 & -106670 & -172540 & $16,5 \%$ & $4,6 \%$ & $-36,3 \%$ \\
\hline «Сибирьтелеком» & 2005 & $31,7 \%$ & 60914 & $16,7 \%$ & 1031957 & -111817 & -126578 & $-30,0 \%$ & $-97,3 \%$ & $-289,7 \%$ \\
\hline «Сибирьтелеком» & 2004 & $61,6 \%$ & 86874 & $17,2 \%$ & 832537 & -56686 & -32477 & $23,4 \%$ & $-74,5 \%$ & $-384,9 \%$ \\
\hline «Сибирьтелеком» & 2003 & $38,2 \%$ & 71459 & $18,0 \%$ & 578579 & -32488 & $\begin{array}{l}-6698 \\
\end{array}$ & $-109,7 \%$ & $-160,2 \%$ & $-110,2 \%$ \\
\hline «Сибирьтелеком» & 2002 & $147,9 \%$ & 81507 & $23,6 \%$ & 116707 & 53972 & 65627 & $-82,0 \%$ & $367,6 \%$ & $2787,3 \%$ \\
\hline «Сибирьтелеком» & 2001 & $229,9 \%$ & 3428 & $19,5 \%$ & 121187 & -20169 & -2442 & & & \\
\hline $\begin{array}{l}\text { «Уралсвязьинфор } \\
\text { м» }\end{array}$ & 2006 & $80,0 \%$ & 94600 & $15,0 \%$ & 1638500 & -151407 & -222311 & $76,7 \%$ & $-7,1 \%$ & $-15,3 \%$ \\
\hline «Уралсвязьинфор & 2005 & $3,3 \%$ & 115530 & $16,7 \%$ & 1534963 & -141414 & -192882 & $6,8 \%$ & $-80,0 \%$ & $-13,2 \%$ \\
\hline
\end{tabular}




\begin{tabular}{|c|c|c|c|c|c|c|c|c|c|c|}
\hline M» & & & & & & & & & & \\
\hline $\begin{array}{l}\text { «Уралсвязьинфор } \\
\text { м» }\end{array}$ & 2004 & $-3,5 \%$ & 122663 & $17,5 \%$ & 1150710 & -78584 & -170374 & $-194,8 \%$ & $0,4 \%$ & $-503,7 \%$ \\
\hline $\begin{array}{l}\text { «Уралсвязьинфор } \\
\text { м» }\end{array}$ & 2003 & $191,3 \%$ & 79180 & $17,9 \%$ & 882123 & -78869 & -28220 & $45,2 \%$ & $-225,3 \%$ & $-128,9 \%$ \\
\hline $\begin{array}{l}\text { «Уралсвязьинфор } \\
\text { м» }\end{array}$ & 2002 & $146,1 \%$ & 119241 & $23,6 \%$ & 238305 & 62927 & 97783 & $125,0 \%$ & $424,9 \%$ & $1141,2 \%$ \\
\hline $\begin{array}{l}\text { «Уралсвязьинфор } \\
\text { м» }\end{array}$ & 2001 & $21,1 \%$ & 9262 & $20,1 \%$ & 142763 & -19371 & -9392 & $64,1 \%$ & $-512,3 \%$ & $-246,7 \%$ \\
\hline «Центртелеком» & 2006 & $50,9 \%$ & 139009 & $15,8 \%$ & 1170294 & -45538 & -135774 & $-24,7 \%$ & $75,3 \%$ & $14,3 \%$ \\
\hline «Центртелеком» & 2005 & $75,6 \%$ & 47229 & $17,8 \%$ & 1300724 & -184152 & -158457 & $91,1 \%$ & $-3,9 \%$ & $10,8 \%$ \\
\hline «Центртелеком» & 2004 & $-15,5 \%$ & -4592 & $18,0 \%$ & 958899 & -177257 & -177557 & $-45,0 \%$ & $-81,1 \%$ & $-91,0 \%$ \\
\hline «Центртелеком» & 2003 & $29,5 \%$ & 27528 & $18,5 \%$ & 676666 & -97878 & -92959 & & & \\
\hline ЮТК & 2006 & $24,8 \%$ & 59736 & $16,2 \%$ & 1209031 & -135856 & -97279 & $-64,7 \%$ & $28,6 \%$ & $13,3 \%$ \\
\hline$\overline{\text { ЮТК }}$ & 2005 & $89,5 \%$ & 33885 & $17,5 \%$ & 1282995 & -190273 & -112205 & $109,2 \%$ & $-89,6 \%$ & $-76,2 \%$ \\
\hline ЮТК & 2004 & $-19,7 \%$ & 57225 & $17,8 \%$ & 883547 & -100355 & -63681 & $-57,1 \%$ & $-11,1 \%$ & $-15,0 \%$ \\
\hline ЮТК & 2003 & $37,3 \%$ & 5390 & $18,4 \%$ & 520921 & -90348 & -55372 & $17,8 \%$ & $-422,7 \%$ & $-539,1 \%$ \\
\hline ЮТК & 2002 & $19,5 \%$ & 36545 & $23,8 \%$ & 226334 & -17283 & 12610 & $33,1 \%$ & $56,2 \%$ & $178,7 \%$ \\
\hline ЮТК & 2001 & $-13,6 \%$ & 5196 & $20,2 \%$ & 221442 & -39495 & -16032 & $-13,1 \%$ & $6,4 \%$ & $22,5 \%$ \\
\hline
\end{tabular}

